\title{
THEORETICAL AND PRACTICAL COMPARATIVE STUDY ON THE USE OF CLAYS FOR THE TREATMENT OF WASTEWATER CONTAMINATED WITH PESTICIDES
}

\author{
Esad Behrami $^{1}$, Kledi Xhaxhiu${ }^{1}$, Bedri Dragusha ${ }^{2 *}$, Avni Berisha ${ }^{3}$, Zehra Hajrulai-Musliu ${ }^{4}$, \\ Arianit Reka ${ }^{5}$, Adelaida Andoni ${ }^{1}$, Xhuljeta Hamiti ${ }^{1}$, Spiro Drushku ${ }^{1}$ \\ ${ }^{1}$ University of Tirana, Faculty of Natural Sciences, Department of Chemistry Tirana, Albania; \\ ${ }^{2 *}$ University of Prishtina, Faculty of Agriculture and Veterinary, Prishtina, Kosovo; \\ ${ }^{3}$ University of Prishtina, Faculty of Natural and Mathematics Sciences, Prishtina, Kosovo; \\ ${ }^{4}$ Cyril and Methodius University in Skopje, Faculty of Veterinary Medicine, Republic of North Macedonia; \\ ${ }^{5}$ University of Tetovo, Faculty of Natural Sciences and Mathematics, Tetovo, Republic of North Macedonia; \\ *Corresponding Author Bedri Dragusha, e-mail: bedri.dragusha@uni-pr.edu; esat.behrami@uni-pr.edu;
}

Received February 2021; Accepted March 2021; Published June 2021;

DOI: https://doi.org/10.31407/ijees11.329

\begin{abstract}
The purpose of this study is to compare the theoretical results which are calculated according to the DFT model, DFT calculations were performed using the code DMol3. To optimize the geometry, the triple numerical set plus the polarization base (TNP) was used. It was also used in combination with the M11L function within the generalized meta gradient (GGA) approximation. The solvent effect $\left(\mathrm{H}_{2} \mathrm{O}\right)$ was incorporated through the conductor-like display model (COSMO). To visualize the adsorption geometry of the two selected adsorbents, namely: benalaxyl and atrazine on the surface of the clay material components, Monte Carlo (MC) simulation was performed, which was performed through the Adsorption Locator module as implemented in the Materials Studio software. 2017. Three types of clay minerals were selected for the simulation: Halloysite $(a=14,220 \AA, b=26,700 \AA, c=19,557 \AA$, AMCSD: 0018093), Kaolinite ( $\mathrm{a}=25,958 \AA, \mathrm{b}=12,950 \AA, \mathrm{c}=17,034 \AA$, AMCSD: 0002868) and Montmorillonite $(\mathrm{a}=25,454 \AA, \mathrm{b}=13,022, \mathrm{c}=40,427$, AMCSD: 0002868). The selected separation plane is based on morphological calculations using the Bravais-Friedel-Donnay-Harker (BFDH) methodology. Achieved results in the experimental aspect realized with the methods: SEM -EDX VEGA3 LMU; Fluorscence Spectrometer X-Ray (XRF), ARL 9900 and GCMS-QP2010S, in relation to the adsorption of Atrazine and Benalaxyl on natural and activated Brayr and Pear clays are in full agreement with the theoretical calculations.
\end{abstract}

Keywords: benalaxyl, atrazine, clay, brari, dardha, monte carlo. 